\title{
The Use of Near-Death Phenomena in Therapy
}

\author{
Dan Punzak, B.S., P.E.
}

ABSTRACT: Though near-death studies have yielded few practical applications, some psychotherapists have used insights from near-death experiences (NDEs) to treat a variety of problems. Using hypnosis, relaxation methods, or electric shock to initiate a conversation with a purported spirit "possessing" the patient, the therapist persuades the spirit to join others in a land of ethereal beauty and light similar to the transcendental realm of an NDE, or simply to go directly into the light. Such techniques are treated as a culmination of the spirit's NDE; that is, the purported possessing spirits had their original death experiences terminated prior to entering the transcendental stage, but instead of returning to their own bodies, they appear to have invaded the bodies of others. Some persons may leave themselves open to invasion through substance abuse or occult practices.

Most near-death experience (NDE) research concentrates on determining exactly what has happened during NDEs, the frequency of their various aspects, verification of information obtained during NDEs, long-term effects on the experiencers, and attempted explanations. Practical application usually aims at helping medical personnel and the general public to accept the existence of such transcendent experiences, thus preventing people who report them from being discredited. I review in this article the work of four therapists who have used aspects of near-death phenomena to treat individuals purportedly "possessed" by spirits, as manifested by hearing voices or inner conversations, severe depression, suicidal thoughts, substance abuse, impulsive or compulsive behavior, phobias, or anorexia nervosa.

Mr. Punzak is a professional engineer with the Illinois Environmental Protection Agency, Division of Air Pollution Control. Requests for reprints should be addressed to Mr. Punzak at 815 Randolph Court, Springfield, IL 62702. 
In discussing their methods, these therapists do not state that they are aware of employing NDE-related concepts in their treatment, but from their written descriptions of their methods, there is little room for doubt that they are dealing with NDE-like phenomena. The therapist usually suggests that the spirit survey its surroundings, and the descriptions provided purportedly by the possessing spirit closely parallel scenes of ethereal beauty, light, or deceased relatives provided by neardeath experiencers (NDErs). Most of the healings reported as a result of this type of therapy are psychological, but physical healings have also been reported in many cases.

Three of the four writers I will discuss, Edith Fiore, Kenneth McAll, and Adam Crabtree, published books in recent years since the popularization of NDEs (Fiore, 1987; McAll, 1982; Crabtree, 1985). The other writer, Carl Wickland, wrote 65 years ago, but his healing methods also involve near-death phenomena (Wickland, 1924). While there exists no actual documentation of the success of these therapies, the same could be said for most techniques in the field of psychotherapy. Concepts, theories, or methods are confirmed by others trying the methods described and reporting positive or negative results. If this new NDE-related method proves successful, it should gain broader attention in the near future.

\section{NDE Classifications}

Particularly appropriate to the therapies being considered is Michael Sabom's concept of the two stages of an NDE (Sabom, 1982). Sabom called the first stage autoscopic or "self-visualizing"; in this stage, the NDErs appear to see their physical bodies and nearby surroundings from a position outside the body. In the second or transcendental stage, the NDEr views scenes of ethereal beauty, brilliant lights or a Being of Light, or recognizes deceased relatives. Sabom reported three possible NDE patterns: an autoscopic experience and then a return to the physical body; a transcendental experience and then a return to the body; or an autoscopic stage, followed by a transcendental stage, followed by a return to the body.

The therapy methods considered here are based on a fourth possibility, that of discarnate spirits refusing to enter, or being held back from, the transcendental realm, and also unable to return to their physical bodies. In an extension of this fourth possibility, such discarnate spirits who do not proceed to the realm of light, that is, the transcendental stage, might then be presumed to cohabit the physical 
body of another living being. Fiore and Wickland referred to "spirit bodies" in such a predicament as "earthbound." NDE-based therapies attempt to remove these presumed cohabitating spirits by helping them enter the transcendental stage that they somehow missed, thereby freeing the patient from a variety of unexplained symptoms.

Some of the healings described imply that the patient is not always an innocent victim of these alleged earthbound spirits. In many cases, the patients appear to have left themselves open to purported "invasion" by activities such as substance abuse or occult practices. These purported "invasions" are commonly called "possession," implying not ownership by the discarnate spirit but rather purported cohabitation in the same physical body, accompanied by an undesirable influence on behavior.

\section{The Healing Methods}

The most recent therapist using near-death phenomena, psychologist Edith Fiore (1987), practices a healing method primarily involving hypnosis of her patient and communication with the purported invading or possessing entity. These entities commonly appear not to have comprehended what has happened, that is, that they have died and are now discarnate, although they often realize that something is awry. While Fiore converses with the purported spirit, it may give some clue as to what happened when in its own body, such as driving on a road and seeing a truck swerve in front of it.

After convincing the purported discarnate spirit that it has entered her patient's body, Fiore's healing technique then parallels the transcendental aspects of an NDE. Fiore asks the alleged spirit to look around for someone it knows or for a light. More frequently the purported spirit reports seeing deceased relatives who appear delighted at being able to welcome another relative to their spirit world. Fiore then asks the spirit to follow the deceased relative into the realm of light. Some alleged spirits see a light only and are encouraged to enter the light; at times they are reluctant to leave, but if they do, the patients are usually relieved of some symptom. It may take several sessions of therapy to get the purported spirit to depart from the patient, and no apparent harm is done if the removal process fails. However, Fiore reported that presumed possessing spirits cannot just be commanded to leave, or they may remain earthbound and invade another person.

The following description by Fiore involves an apparent masculine spirit in a woman's body and removal through a reasoned argument: 
Within seconds of addressing any spirits that may have been with her, I noticed a distinct shift from a blissful expression to one of total agitation $-\mathrm{a}$ "violent" reaction. There was my evidence! Her crying was so strong that I almost discontinued the recording. However, I invited in the spirit's loved ones, as I routinely do, and witnessed the entity calming down. I continued and shortly observed the tension in her body abruptly release. I ended the depossession and brought her out of trance. ...

Since he probably had not left, I asked her to close her eyes again, and to monitor the reactions she felt as I talked specifically to that spirit. Tears streamed down her face as I pointed out how hard it was for a man to be trapped in a female body. Then I invited him to go with his loved one, perhaps his mother, to the spirit world where he would be in his own strong, healthy, male body. (Fiore, 1987, pp. 58-59)

The following example involves a corporate vice-president, Peter, who frequented taverns atypical of a man in his position. Fiore discovered the apparent spirit of a blue-collar worker, Lou, cohabitating his body:

It finally became clear to Lou what had really happened. He said he was sorry for the harm he had done to Peter and asked how he could move on. I told him to look around to see if there were anyone he knew. He saw his wife, who he thought had died hating him for his drinking. Realizing she had forgiven him, he happily left with her. (Fiore, 1987, p. 74)

Adam Crabtree (1985) has also used a removal technique similar to Fiore's in treating his clients. When either deeply relaxing or hypnotizing a patient, he has talked to a purported invading spirit and convinced it to leave his client and join deceased relatives or go to a light. In contrast to Fiore, whose earthbound spirits are often unidentified, Crabtree has reported that the alleged possessing spirits are often deceased relatives, such as a woman who, at death, seemed to enter her granddaughter.

In some cases Crabtree claims it is important to understand why the relationship between the purported spirit and the client has occurred. In one instance, a woman named Susan, who was having difficulties in relationships with men, appeared to be possessed by the spirit of her deceased father, John, who had abused her when she was a child. The following is Crabtree's account of his success in convincing John that his own body had died and he was living within his daughter's body:

We suggested he consider that up to now he had been looking "down" at Susan and the events of this world, completely preoccupied with 
earthly concerns. He would now find that he could look "up" and if he did, he would see new things.

John followed our suggestions and soon began to see a "light." Eventually he recognized human presences in that "light": his aunt and his mother, both long deceased. John realized that he would have to leave Susan, now that they had reached the point of resolution, yet he was still afraid to go on, even though he wanted to. Then one day after about six weeks of sessions, we called upon John and he was not there. He had taken the final step on his own, and Susan was free of possession. (Crabtree, 1985, p. 156)

Carl Wickland's book, Thirty Years Among the Dead, was written in 1924. A medical doctor, Wickland also classified himself as a spiritualist, and his healing method involved using his wife as a medium. Instead of hypnotizing his patients, he would give them an electric shock that caused the purported invading spirit to leave the patient and enter Mrs. Wickland's body, seated in a trance near the patient. Wickland would then "interview" the alleged spirit in his wife's body.

Mrs. Wickland claimed to have no knowledge of the conversations that occurred while the spirit was allegedly using her body, and she apparently experienced no long-term ill effects. Wickland claimed that when his wife was taken over by an obsessing spirit (another term he used for a purported possessing spirit), she would sometimes speak in foreign languages she did not know. Wickland would try, as does Fiore, to convince the alleged spirit that it had lost its own body and had entered another, and would suggest that it look around for people it knew when alive, usually relatives. Except for a few cases, the purported spirit would usually see relatives and leave with them.

One case involved first seeing relatives, then beautiful scenery. The description sharply parallels accounts from NDEs:

\begin{abstract}
What beautiful things I see! Are they not beautiful! This is not a dream. . . . Just look at those beautiful homes on that hillside! Look at those lovely walks, beautiful lakes and hills, lovely flowers that bloom everywhere! Isn't it beautiful! Can I go there? . . . Look at the lights! Are they not beautiful! They are singing and vibrating into different shades and tunes. The colorings are wonderful. (Wickland, 1924, pp. 88-89)
\end{abstract}

The concept of deceased relatives influencing a family member is discussed further in another book, Healing the Family Tree, by Kenneth McAll (1982), an English psychiatrist. McAll is a professed Christian, and his method of healing does not involve hypnosis or talking to a purported possessing entity, but rather holding an Anglican reli- 
gious service for deceased ancestors identified as a possible cause of the problem. The Eucharist service includes asking Christ to cleanse the bloodlines of the living and the dead, forgiving deceased relatives as well as asking them for forgiveness, and placing the family tree on an altar and having the patient or another attendee receive the Eucharist in the deceased person's name. At the conclusion of the service, the focus is changed from the dead to the living.

The function of this service, as I conceptualize it, is to enable the deceased person's spirit to enter the transcendental realm of light, which then frees the patient from apparent control. McAll describes the process as freeing the person from ancestral control. In drawing up the family tree, factors McAll may look for in deceased relatives to be prayed for include unacceptable behavior; sudden death; a death after which no committal service was held; and an abortion, miscarriage, or stillbirth. These latter three causes were identified by McAll in over 40 percent of the 1400 healings he has observed.

The following are two examples of healings reported by McAll that particularly exemplify how his healing relates to NDEs. During a Eucharist service held in England for an American woman whose son was schizophrenic, McAll envisioned at the side of the church a dark hunchback figure. When the service ended, this figure seemed to float upward and join a number of gowned figures who greeted him, saying, "We will look after you." When McAll later explained his vision to the others, the American woman identified the hunchback as her father, who had committed suicide. She had not previously told McAll about him. Later, the woman reported that her son's schizophrenia had been healed.

In another case of hearing voices, a woman named Maggie had "conversations" with an invisible friend named Peter, who frequented a certain riverbank. She described him as unkempt, and he was even referred to as Peter the Tramp by the local people who saw him at the riverbank, from which he would often reportedly vanish. During a Eucharist service held on the riverbank, Maggie saw Peter, dressed in white, rising above them and thanking those praying for his release. He then disappeared, and Maggie never saw or heard from Peter again. This case may represent purported attachment of a spirit to a place, rather than possession.

\section{Apparent Reasons for Remaining Earthbound}

There are two important factors to consider in asking the causes for what I call invasive disorders, but which Fiore and others call possession. First, why did the purported spirit of the deceased person seem to 
remain earthbound? And secondly, are there any similarities in the circumstances of the people who seem to have been invaded?

Though there are exceptions, the impression from reading the works of these four therapists is that alleged earthbound spirits frequently have died an abnormal and/or rapid death and are confused. Accidents are one possibility of an abnormal or early death, but in many of Fiore's cases, the purported earthbound spirit is that of a person with a drug or alcohol addiction, or someone who has committed suicide. It appears that the desire for excess alcohol, drugs, food or sex in the alleged discarnate spirit may continue in the body it appears to have invaded. These purported discarnate spirits seem to choose persons who already have a strong desire for alcohol or are alcoholics. Multiple invasions have also been reported; Fiore once identified the alleged spirits of 18 alcoholics in a reformed alcoholic woman who had not had a drink in four years.

Similarly, purported spirits of persons who have committed suicide may appear to carry depression into their victims. Fiore listed several other reasons for remaining earthbound: obsessive attachment to living persons such as a parent to a child, attachment to places, a sense of unfinished business, and revenge. According to Wickland (1924), persons who commit suicide, even though apparently influenced by an obsessing spirit, almost always remain earthbound themselves, usually at least for a time that would have been their natural lifespan. That notion is consistent with Kenneth Ring's finding that persons who attempt suicide do not usually proceed to the last two stages of an NDE, seeing and entering the light (Ring, 1980).

\section{Causes and Symptoms of Purported Possession}

What are the circumstances of persons purportedly possessed by earthbound spirits? Ordinarily, a normal healthy person would not be invaded, but Fiore (1987) has identified situations that may open a person to invasion, including illness, extreme fatigue, anesthesia, head injuries and unconsciousness, excessive alcohol consumption, substance abuse, and occult activities such as automatic writing or use of a ouija board. Alleged possession may occur in hospitals, because people die there and the patients are often in a weakened condition.

Symptoms that lead Fiore to suspect invasion include (1) persistently low energy level; (2) personality changes or rapid mood swings, especially after substance abuse; (3) inner conversations or thoughts, especially if commands are given in a berating tone: (4) substance abuse, 
including "recreational drugs," and inability to give them up despite strong effort; (5) extreme impulsiveness; (6) breaks in consciousness; (7) inability to concentrate, being "in a fog"; (8) anxiety or depression for no apparent reason; (9) sudden onset of physical problems without an obvious cause; or (10) emotional or physical symptoms while reading Fiore's book, including pounding heart, sweating, difficulty breathing, trembling, or tingling.

In addition to the above symptoms, Fiore's patients, following treatment, have reported relief from memory and emotional problems, depression, suicidality, phobias, obesity, marital and other interpersonal difficulties, and homosexuality and paraphilias. The latter two are caused, in Fiore's opinion, by invasion by discarnate spirits of the opposite sex. Fiore claims that about $70 \%$ of her patients suffer from these invasions, although that figure may be high due to the nature of referrals from other psychologists familiar with her work.

Crabtree (1985) states that clients might simply tell him they feel possessed by an alien entity that would subtly communicate with them, but he claims that the client does not have to believe in the objective reality of possession for symptom relief to occur. Crabtree reports that he has treated about 50 cases of apparent possession in seven years of practice, a frequency much lower than Fiore's. He has not reported having used this treatment for substance abuse. His results range from minimal change to radical improvements.

McAll (1982) commonly reports healing schizophrenia, primarily the symptom of hearing voices inside the brain; anorexia nervosa; and phobias. His psychological healings are very frequently accompanied by physical healings, and he has reported apparent possession in children whose parents were involved in occult practices or abortion.

Wickland (1924) reported a broad scope of problems in his patients that lapsed after the departure of purported earthbound spirits, including alcohol addiction, depression, suicidality, criminal tendencies, insanity, and sometimes personality traits and symptoms of the person who has died, as in the case of a patient with unexplained neck pains whom Wickland claimed had been obsessed by the spirit of man who had died of a neck injury.

Wickland reported that stubborn spirits who cannot be convinced by reasoned argument to leave and to proceed to the transcendental stage may be taken away by apparent spirit helpers for educational purposes; Fiore reported a similar phenomenon. Such spirit helpers were more important to Wickland, whose wife purportedly had been temporarily cohabited by the discarnate spirit, than for Fiore, who could wait for a later session with the patient. Wickland claimed to have verified some details provided by the alleged spirit, but other therapists have not done so. 


\section{Near-Death Research}

Some of the implications of these therapeutic techniques are supported by near-death research or by individual reports of NDEs. Raymond Moody wrote of a realm of bewildered spirits, in which several NDErs reported observing confused beings who seemed "unable to surrender their attachment to the physical world," that is, "they seemed bound to some particular object, person, or habit" (Moody, 1977 , p. 18). Such beings appeared "dulled" and remained in their perplexed state until they had solved whatever problem or difficulty had kept them here.

To one NDEr, these dulled spirits appeared more humanized than the figures in the brilliant light. They seemed sad and depressed, their heads bent downward, and constantly moved aimlessly about as if caught between the physical and the spiritual world. Another NDEr reported seeing a spirit looking down on a person in his physical body, like a mother looking after her son who was unaware of her presence.

George Ritchie, now a psychiatrist, had an NDE in 1943 that differed from many others in that, following a typical autoscopic stage, he proceeded on an extended earth journey accompanied by a Being of Light. During this journey, Ritchie observed spirits of deceased persons caught up in their former habits or negative emotions, and scenes in which deceased spirits tried to interact with the living, who were unaware of their presence. In several scenes the spirits of persons who appeared to have committed suicide were apologizing to still-living family members for the grief their suicides had caused. In another scene spirits tried repeatedly to grab a cigarette that living persons were smoking, but the spirits' hands passed through the cigarette, leaving their desire unsatisfied.

A third scene reported by Ritchie suggests a moment of invasion as a result of intoxication. Earthbound spirits, unaware that they had died and could not be seen, heard, or felt, lingered in a dingy bar close to drinking sailors, whom Ritchie could distinguish from the spirits by a "cocoon of light" or "aureole" around their living bodies. Ritchie saw some of the spirits attempt to pick up a shot glass and quarrel over glasses that their spirit bodies would pass through.

I watched one young sailor rise unsteadily from a stool, take two or three steps, and sag heavily to the floor. Two of his buddies stooped down and started dragging him away from the crush.

But that was not what I was looking at. I was staring in amazement as the bright cocoon around the unconscious sailor simply opened up. It parted at the very crown of his head and began peeling away from his head, his shoulders. Instantly, quicker than I'd ever seen anyone 
move, one of the insubstantial beings who had been standing near him at the bar was on top of him. He had been hovering like a thirsty shadow at the sailor's side, greedily following every swallow the young man made. Now he seemed to spring at him like a beast of prey.

In the next instant, to my utter mystification, the springing figure had vanished. It all happened even before the two men dragged their unconscious load from under the feet of those at the bar. One minute I'd distinctly seen two individuals; by the time they propped the sailor against the wall, there was only one.

Twice more, as I stared, stupefied, the identical scene was repeated. A man passed out, a crack swiftly opened in the aureole round him, one of the nonsolid people vanished as he hurled himself at that opening, almost as if he had scrambled inside the other man. (Ritchie, 1978 , pp. 60-61)

Near-death research may be helpful in preventing purported invasion by discarnate spirits simply by convincing more people that there is life after death. Fiore and Wickland both emphasize that belief in life after death is likely to (1) decrease a discarnate spirit's confusion that might cause it to seek another physical body to inhabit, and (2) increase a discarnate spirit's comfort at seeing deceased relatives or a light and advancing toward them.

While there may be differing explanations for the success of these NDE-related therapies, their rationale is based on encouraging a purported discarnate spirit to proceed to the transcendental stage of an NDE rather than to remain on the earth plane and cohabit another person's body. The potential benefits of such "completing the death experience" therapy for a variety of illnesses warrant, at the least, further study.

\section{References}

Crabtree, A. (1985). Multiple man: Explorations in possession and multiple personality. New York, NY: Praeger.

Fiore, E. (1987). The unquiet dead. Garden City, NY: Dolphin/Doubleday.

McAll, K. (1982). Healing the family tree. London, England: Sheldon Press.

Moody, R. A. (1977). Reflections on life after life. St. Simon's Island, GA: Mockingbird.

Ring, K. (1980). Life at death: A scientific investigation of the near-death experience. New York, NY: Coward, McCann and Geoghegan.

Ritchie, G. G., with Sherrill, E. (1978). Return from tomorrow. Waco, TX: Chosen Books.

Sabom, M. B. (1982). Recollections of death: A medical investigation. New York, NY: Harper and Row.

Wickland, C. A. (1924). Thirty years among the dead. Los Angeles, CA: National Psychological Institute. 